\title{
Histórias Que (Não) Curam: Sobre Narrativas em Hipnose Clínica
}

\author{
Stories that (don`t) Heal: on narratives in clinical hypnosis
}

Resumo: $O$ presente artigo retoma o tema da hipnose criticando algumas das principais crenças que levaram ao seu desuso em Psicologia Clínica. Ao mesmo tempo, busca levantar outros princípios que tornem possível e eficaz sua utilização clínica. Para tanto, parte-se de um estudo de caso de Milton Erikcson, de onde são destacadas e problematizadas duas questões essenciais: a substituição dos sintomas e a qualificação da autoridade do terapeuta. O primeiro ponto é discutido em torno da crítica sobre a superficialidade da hipnose, o que remete a uma visão mais ampla da subjetividade, onde aparência e essência desenvolveriam uma relação complexa e não-linear. A discussão do segundo ponto considera que a autoridade do terapeuta é necessária não para se opor diretamente ao sintoma, mas para criar condições em que a auto-regulação do sujeito crie soluções próprias para seus problemas. Para concluir, o artigo sustenta que o tema da hipnose, por suas implicações históricas, clínicas e epistemológicas, consiste em um desafio para a Psicologia que remete à revisão da própria história de seu projeto de ciência. Palavras-Chave: Hipnose, Psicologia Clínica, epistemologia, Freud, Erickson.

Abstract: The present article brings back the very subject of hypnosis by criticizing some of the main beliefs that promoted the lack of its use in Clinic Psychology. Meanwhile, the article tries to raise some other principles that make the possibility and efficiency of the usage of clinic-wise hypnosis easier. For that matter, we start off with the study of Milton Erikson's case, from which two aspects are highlighted and put in perspective: the substitution of the symptoms and the qualification of the therapist authority. The first revolves around the superficiality of hypnosis, which takes us to a broader view of subjectivity, where appearance and essence would develop a complex and non-linear relationship. The discussion of the second aspect ponders that the authority of the therapist is not needed in direct opposition to the symptoms, but in creating conditions in which patients' self-regulation can establish personal solutions to the their own problems. To conclude, the article states that the theme of hypnosis, for its clinical, epistemological and historical implications, consists of a challenge to Psychology that deals with the review of its own historical science project.

Key Words: Hypnosis, Clinical Psychology, epistemology, Freud, Erickson.

\section{Maurício Neubern}

Doutor em Psicologia Psicólogo Clínico. Pesquisador Autônomo.
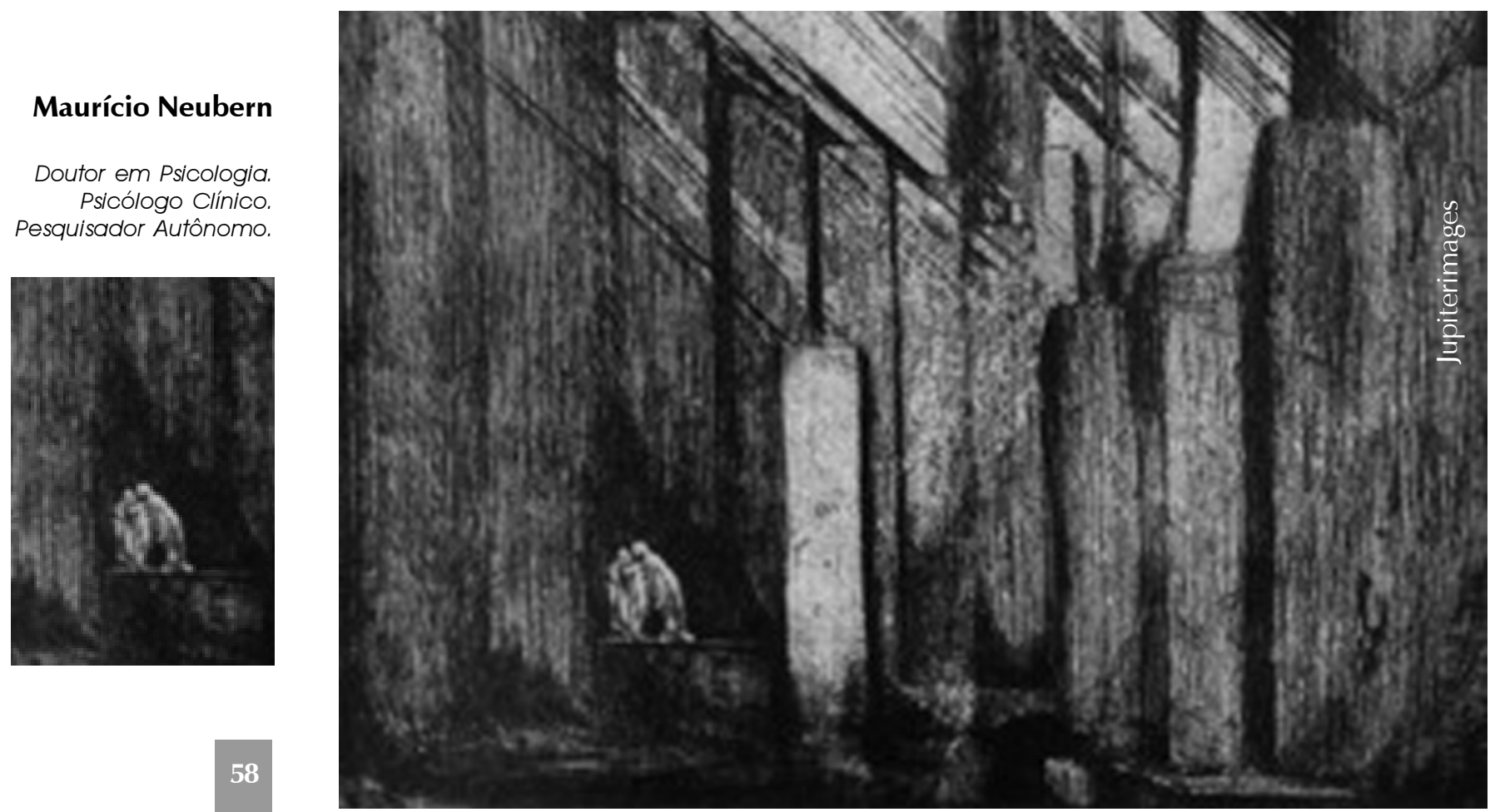
A compreensão histórica da hipnose na prática clínica é, em geral, vista como um processo que passou inicialmente por um período de afã e entusiasmo e culminou com o abandono e o ostracismo (Carroy, 1991; Chertok, 1989). A participação da Psicanálise, nesse sentido, foi decisiva, pois, embora reconhecesse sua herança com tais abordagens, preconizou seu abandono sob a alegação de haver desenvolvido um método mais eficaz e confiável, capaz de ir além das aparências e lidar com as causas dos conflitos psíquicos (Freud, 1905; 1917-a). As conseqüências desse processo foram drásticas para o uso clínico da hipnose, que passou a ser marcado por um conjunto de numerosos preconceitos, tais como a substituição do sintoma, a dependência e submissão quanto ao hipnotizador, a superficialidade de seu uso, que jamais chegaria às causas dos problemas, os riscos de suicídio associados a sua prática, a inconsciência total e ausência de senso crítico, dentre outros (Melchior, 1998; Yapko, 1992). Em outras palavras, a herança maldita que recaiu sobre ela foi tamanha que passou a ser vista não apenas como um instrumento inútil mas também perigoso, que poderia ser facilmente substituído por um método mais racional e seguro.

Entretanto, essa forma de conceber a história omitiu muitos pontos de considerável importância, a começar pelas vicissitudes do projeto científico que animou Freud na construção da Psicanálise (Chertok \& Stengers, 1989; 1999). Suas preocupações não eram apenas relativas aos fracassos terapêuticos dos métodos hipnóticos, mas estavam voltadas, sobretudo, para o desejo de obter testemunhos confiáveis do mundo psíquico que pudessem alçar sua abordagem ao caráter de uma ciência, mesmo que distinta da proposta experimental das psicologias da época. Nesse sentido, nada seria mais contra-indicado do que a hipnose em que os processos de sugestão poderiam fazer facilmente com que os sujeitos, de algum modo, acatassem a vontade do terapeuta ao invés de revelar a veracidade de seus conflitos. Sendo assim, foi contra essa possibilidade sempre presente de complacência que a noção de inconsciente se desenvolveu e ganhou espaço, pois o inconsciente seria capaz de resistir à vontade de terceiros, aos comandos e desejos conscientes do sujeito e, assim, mostrar um verdadeiro jogo de forças autônomo que estaria subjacente à produção dos sintomas. É como se a noção de inconsciente possibilitasse, para a abordagem dos fenômenos psíquicos, uma legítima separação entre sujeito e objeto. O aparelho psíquico poderia, então, tornar-se uma espécie de laboratório capaz de revelar as realidades da alma humana ${ }^{1}$ e, ao mesmo tempo, assegurar um método superior em eficácia às abordagens sugestivas. Freud (1917-a) concretizaria, com isso, os ideais científicos de um acesso privilegiado e objetivo ao real e, em conseqüência, a possibilidade de controle do mesmo por meio de curas mais efetivas.

Contudo, o que praticamente não se mencionou foi que esse triunfo da Psicanálise em termos de eficácia jamais se efetivou, o que foi mesmo reconhecido por Freud ao final de sua vida (Freud, 1937), mas não ganhou eco entre seus seguidores (Chertok \& Stengers, 1999). Não interessava que as curas efetuadas pela Psicanálise não fossem mais numerosas, seguras e duradouras que as de outros métodos. Mesmo que o controle possibilitado por um acesso privilegiado ao real não tivesse jamais ocorrido, os adeptos da Psicanálise, em sua maioria, continuaram a compreendê-la como um método superior e a desqualificar as demais abordagens de caráter sugestivo. A maldição estava já lançada, e como as instituições de Psicanálise e Psicologia Clínica lutavam ferozmente por espaços sociais, tornou-se necessário que diversos mecanismos fossem desenvolvidos para que temas considerados subversivos fossem evitados e a autoridade dos mestres fosse colocada acima do debate e da discussão abertos (Neubern, no prelo; Stengers, 2001). Desse modo, fora da marginalização, os únicos lugares possíveis para a compreensão da hipnose foram os livros de história, onde não haveria mais do que algumas menções referentes a métodos bizarros que logo seriam superados por abordagens racionais e confiáveis.

Diante do exposto, o objetivo deste artigo é duplo, pois visa, ao mesmo tempo, a desconstruir e questionar algumas crenças que se colocam como obstáculos ao uso clínico da hipnose ${ }^{2}$, como também levantar outros pressupostos que possam permitir esse uso. A discussão ocorrerá, sobretudo, em nível teórico-epistemológico a partir de um estudo de caso de Milton Erickson (1954), cuja relevância permite levantar questões de considerável pertinência para os propósitos do artigo. Entretanto, algumas breves advertências devem ser feitas. Primeiramente, deve-se considerar que tal caso é tomado apenas como ilustração que permite gerar questões pertinentes para o trabalho, e não como exposição sistemática da diversificada e complexa obra de Erickson, o que pode ser encontrado em outras fontes (Erickson \& Rossi, 1980). Em segundo lugar, é necessário que se considere que uma amostra da obra desse autor $^{3}$ é aqui tomada como ilustração, sobretudo devido ao caráter subversivo de seus pressupostos quanto a inúmeros princípios tidos como certezas por grande parte das escolas de Psicologia Clínica (Neubern, 2002). Trata-se, portanto, de uma tentativa de compreender que a hipnose não é um objeto isolado, mas está necessariamente envolvida com pressupostos e princípios que podem fazer a diferença em sua utilização.
1 Essa possibilidade de revelar a realidade é o que teria permitido a Freud colocar-se como herdeiro de Copérnico (Freud, 1917b), pois enquanto este teria ferido o narcisismo do homem mostrando que a Terra não éo centro do universo, aquele tê-la-ia feito ao mostrar a majestosa influência e domínio do inconsciente na vida das pessoas.

2 Essas crenças provêm, em sua maioria, da Psicanálise, mas encontram-se de tal modo difundidas que abrangem a grande maioria das escolas de Psicologia Clínica. Assim, embora as citaçóes psicanalíticas sejam tomadas como fio condutor; as críticas a elas traçadas possuem um alcance bem mais amplo.

3 Milton H. Erickson (1901 1980) é um dos principais responsáveis pela retomada da hipnose no século XX. Embora nunca tenha sistematizado em termos teóricos a sua obra, suas contribuições clínicas foram numerosas e têm suscitado reflexões da mais alta importância, que ainda estão longe de serem esgotadas Bellet, 1992; Halev, 1993; Melchior 1998; Neubern, 2003). 


\section{O Sr. "A"}

O Sr. "A", 59 anos, era um trabalhador braçal pouco instruído, que veio encaminhado para ajuda psiquiátrica devido a uma paralisia histérica no braço direito. Já havia completado 34 anos de serviço, e, caso não se recuperasse de seu problema sem sentido e não chegasse aos 35, seria prejudicado em sua aposentadoria. A companhia só havia permitido uma semana de hospitalização, e como o Sr. "A" era muito pouco comunicativo, não foi possível o levantamento de sua história. Enquanto, na vigília, seu braço permanecia rígido e sem movimento, durante o sono, percebeu-se que relaxava e voltava ao normal, o que confirmou o diagnóstico inicial. Com a colaboração de dois amigos médicos, Erickson conduziu uma pseudodiscussão diante do paciente sem que os participantes se dirigissem a ele. Nessa discussão, em tom pessimista e recheada de termos técnicos, todos concordavam que o caso era o de uma síndrome de inércia, e que seu desenvolvimento

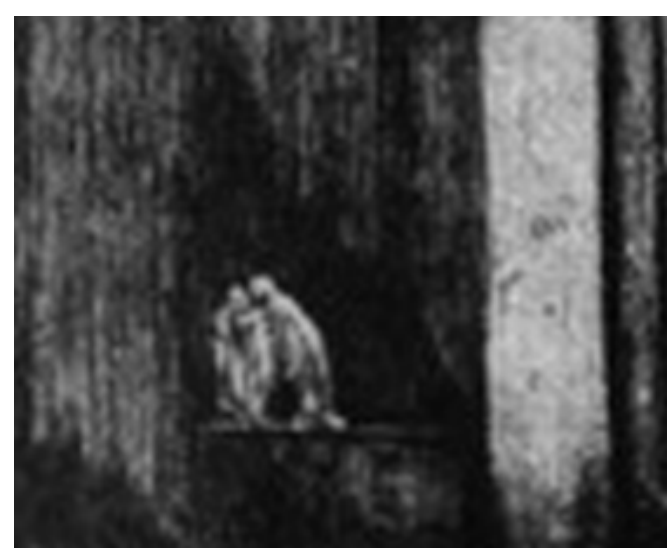

seria o seguinte: primeiro, ocorreria certo relaxamento no ombro dentro de dois dias, permitindo alguns movimentos de braço. Infelizmente, isso seria acompanhado por uma penosa sensação no pulso direito. Em seguida, o cotovelo iria perder sua rigidez, mas ela ficaria concentrada no pulso. Ao fim de uma semana, seus dedos iriam relaxar, mas o pulso continuaria com incômodo. A rigidez do pulso traria uma sensação de fadiga, mas apenas durante a utilização do braço direito. A encenação foi repetida com o sujeito em transe, confirmando-se o anteriormente dito, com a diferença de que, nessa situação, os médicos enfatizaram que já estavam ocorrendo algumas mudanças em termos de relaxamento de alguns nervos paralisados. Para que o paciente não se sentisse atacado, os médicos concordaram que se tratava de um problema físico. Durante os outros dias, acompanharam o paciente e expressaram sua satisfação em ver que o diagnóstico se confirmava. O Sr. "A" saiu da internação e, apesar de certa sensação de fadiga no pulso, pôde voltar ao trabalho normalmente, sem o reaparecimento da sintomatologia anterior.

\section{A Substituição de Sintomas: de Causas a Construções}

Na concepção terapêutica de Freud, enquanto a hipnose poderia ser comparada a um procedimento cosmético, a Psicanálise seria semelhante a uma cirurgia (Freud, 1917-a, pp. 523 - 527), isto porque a superficialidade das abordagens sugestivas não permitiria o acesso ao jogo de forças dos conflitos inconscientes, o que teria, como provável conseqüência, o retorno da sintomatologia habitual ou o aparecimento de uma nova. Os resultados das terapias hipnóticas e sugestivas apresentavam, nesse sentido, um considerável problema: quando não eram transitórios, como ocorreria na maioria das vezes, poderiam até ser duradouros, mas contariam com o inconveniente de permanecerem inexplicados. Desse modo, seria necessário que o terapeuta, por meio do trabalho da transferência e resistência, fosse além das aparentes manifestações para chegar ao núcleo do conflito, geralmente ligado ao passado vivido dos sujeitos. $O$ retorno de um sintoma ou o aparecimento de um novo estaria, portanto, associado ao fracasso do trabalho, que não teria sido capaz de chegar à raiz do problema. Mais uma vez, Freud repetia a racionalidade científica dominante, pois interessava-se pelas leis gerais além das aparências, considerando estas últimas como simples conseqüências ou resíduos desprovidos de importância.

Por outro lado, um dos primeiros questionamentos que o caso acima apresenta é o de uma mudança duradoura sem que tenha ocorrido uma investigação arqueológica com o sujeito no sentido de trabalhar o conflito subjacente ao sintoma. Sem dúvida, é possível argumentar que tal caso poderia fazer parte, talvez, do reduzido grupo de curas que permanecem inexplicadas e que a própria condição em que ocorreram (tempo escasso, contexto hospitalar etc) teria levado o terapeuta a uma abordagem rápida, embora ainda permanecesse desejável um trabalho mais profundo. Seria mesmo possível dizer que a cura não teria sido completa e que a substituição de sintomas apenas teria permitido uma nova solução de compromisso. Todavia, mesmo mantendo-se essa perspectiva causal, pode-se notar que esse tipo de caso é bem mais numeroso do que se supõe (Erickson \& Rossi, 1980; Haley, 1993), o que traz questionamentos incisivos para o pensamento psicanalítico, pois, se as supostas raízes do conflito são condição para que a terapia chegue a bom termo, isto é, com mudanças patentes e 
duradouras, como poderiam ser compreendidos tais casos ou ainda outros em que os sintomas ${ }^{4}$ são eliminados por completo? Sendo assim, não é sem razões que essa perspectiva causal, linear e unilateral entre sintomas e conflitos tem sido questionada por autores de diversas abordagens (Anderson, 1997; Gonzalez Rey, 2002; Melchior, 1998; O'Hanlon, 1994), o que leva a supor que o problema, ao contrário da certeza que se supôs possuir, ainda esteja em aberto.

Dentre as várias questões que esse caso pode levantar, uma pode ser discutida, aqui, com um pouco mais de atenção, sem que se busque, com isso, a pretensão de esgotar o assunto. Trata-se da construção narrativa ${ }^{5}$ que tem lugar em um cenário específico, que procura reconhecer o sujeito, e, ao mesmo tempo, sugerir-lhe mudanças. $O$ terapeuta efetivou uma leitura que buscou, de certo modo, atender uma grande quantidade de necessidades e sentidos do contexto e do próprio paciente. Por um lado, havia uma necessidade irrefutável de resultados em curto prazo, a começar pela pressão exercida pela empresa, que só lhe havia permitido uma semana para tratar do seu problema, tachado por ela de sem sentido. A situação era delicada e poderia trazer sérios prejuízos à aposentadoria do paciente, o que certamente o fazia sofrer bastante.

Mas, ao mesmo tempo, foi necessário que o terapeuta considerasse o próprio funcionamento subjetivo do sujeito a fim de desenvolver uma abordagem adequada para o mesmo. O Sr. "A" era um homem pouco instruído, habituado ao trabalho braçal, pouco voltado a explanações verbais e que, além de se sentir ameaçado pela empresa, estava sendo desqualificado em seu sofrimento. Assim, ao invés de preconizar um método universal, como o fazem a grande maioria das escolas de Psicologia Clínica, o terapeuta trabalhou de modo a construir um contexto específico para tais pontos: o paciente não precisaria falar, mas teria a opção de observar a discussão dos especialistas sem se endereçar a eles; três médicos foram destacados para reconhecer seu sofrimento, utilizando suas autoridades para ratificar que se tratava de um problema legítimo; seu sofrimento foi confirmado repetidas vezes, mas permeado por diversas sugestões de mudança, o que o interessava sobremaneira, pois garantiria seu retorno normal ao trabalho. Dito de outro modo, o terapeuta desenvolveu um contexto que permitiu abordar a diversidade de significações e sentidos configurados no próprio cenário do sujeito, não cedendo à tentação de lhe impor uma teoria, cujas significações muitas vezes são estranhas à singularidade dos sujeitos (Gergen \& Kaye, 1998; Gonzalez Rey, 2002). Logo, compreende-se que, muito provavelmente, o uso da hipnose foi eficaz, não por uma técnica em si mesma, mas, dentre outros pontos, pela correta consideração do problema da legitimidade.

O leitor atento poderia argumentar, com propriedade, que tal princípio é comum às terapias pós-modernas (Anderson, 1997; White \& Epston, 1993) e que, por isso, a hipnose poderia consistir em um instrumento dispensável. Entretanto, o que a hipnose acrescenta, e muitas vezes de forma consideravelmente rápida, é uma relação específica em nível inconsciente (Erickson, 1952). Note-se que, no exemplo discutido, as narrativas construídas para o paciente são sugestivas em ambos os momentos (com o paciente acordado e em transe), isto é, ao mesmo tempo em que confirmam algumas expressões óbvias do problema (como as paralisias, o sofrimento, a permanência do sintoma e o pessimismo), elas apontam para uma evolução na direção da cura. Tudo é feito sob a roupagem de termos técnicos, apontando uma progressão permeada por percalços que, ao final, ainda manteria uma seqüela da falsa síndrome. No entanto, o momento da hipnose marca uma certa ruptura (o transe) que é aproveitada para transmitir ao sujeito a mensagem que as mudanças já estavam acontecendo, pois alguns nervos já estavam relaxados. Mais uma idéia de mudança era transmitida em uma situação ritualizada, mas, dessa vez, aproveitando-se as várias possibilidades disponíveis de conexões próprias ao inconsciente.

Nessa perspectiva, a hipnose ganha um aspecto construtivista (Melchior, 1998; Robles, 2001), uma vez que as narrativas desenvolvidas pelo terapeuta, ao invés de visarem uma revelação da vida psíquica, permitem que o sujeito, por meio do inconsciente, tome-as para si, sintetize-as com seus próprios recursos e mobilize-as a seu favor. Em outros termos, diante da multiplicidade de processos e sentidos inconscientes do sujeito, a atitude do terapeuta não seria propriamente a de alguém que buscasse um acesso privilegiado à realidade psíquica, mas a de alguém que, contemplando a legitimidade desses cenários, aproveitasse o potencial de articulações complexas do inconsciente para construir o novo, mesmo que a partir do terreno já familiarmente conhecido pelos sujeitos. Embora essa atitude pareça condenar o ideal científico presente na Psicologia, ela pode estar remetendo a reflexão à necessidade de novas racionalidades para a compreensão da subjetividade humana (Neubern, 2003; no prelo).

Uma das primeiras rupturas nesse sentido refere-se à própria noção de causa, que recebe questionamentos incisivos a partir de casos como o aqui discutido. Isso porque a tradição moderna de psicoterapia ${ }^{7}$ caracterizou-se tanto pela
4 Sintomas não apenas no sentido de comportamentos observáveis, mas também de processos subjacentes como, por exemplo, angústia e ansiedade. Principalmente nesses casos, não se trata de uma eliminação completa, mas de uma nova condição em que o sofirimento seja administrado com mais facilidade pelo sujeito.

5 Trata-se da organização de um fluxo de experiência por meio do discurso, de palavias, símbolos e metáforas em uma seqüencia temporal e significativa. Ela constrói na linguagem o ainda não dito, $o$ inédito, o novo, em um arranjo que integra eventos distintos e sem ligação. Pode utilizar-se, para tanto, de epopéia, drama e história (Grandesso, 2000).

6 É certo que, enquanto conceito, a noção de inconsciente é bastante precária e frágil na grande maioria dos autores que buscaram teorizar sobre a hipnose (Stengers, 2001). Contudo, as noções de Erickson, embora também precárias em termos teóricos, são bastante úteis em termos clínicos, sobretudo por mostrar diversas possibilidades de conexões, aprendizagens e mudanças que os sujeitos realizam em seu cotidiano.

7 Trata-se das escolas imbuídas da perspectiva de um conhecimento privilegiado do real, o que, no fundo, foi inspirado pela pretensão de um conhecimento científico. Tais seriam, por exemplo, as três forças da Psicologia, para as quais a realidade psíquica deveria ser revelada por métodos científicos. Já as escolas pósmodernas enfatizam a realidade como uma construção (Gergen, 1996), como é o caso do construcionismo social e dos construtivismos. 
elucidação empírica das essências (Gergen, 1996) como pela desvalorização das manifestações mais aparentes das expressões do sujeito. Enquanto as causas estariam na essência, de onde derivaram, por exemplo, as noções de estrutura de personalidade, os efeitos estariam em um nível mais aparente e transitório. Mas o que o caso acima destaca é um trabalho bem-sucedido, voltado e reconstruído apenas em termos do aparente, isto é, a linguagem, o sintoma e suas relações com o corpo, tendo também abordado com pertinência os sentidos ${ }^{8}$ do cenário do paciente. Nesse sentido, tanto a legitimidade como a eficácia levam a supor que o desenvolvimento de sentidos e significados dos sujeitos não obedece a uma relação linear, mas complexa, e que suas configurações podem estar relacionadas a diferentes níveis, tanto o subjacente como o aparente. Não é sem razões que, em outros casos clínicos, o próprio Erickson fez intervenções que poderiam ser compreendidas como relacionadas às essências (Erickson \& Kubie, 1941).

Em suma, pela própria superficialidade com que tantas vezes se acusou a hipnose (Freud, 1905; 1917-a), pode-se retomar uma reflexão que aponte para uma subjetividade muito mais complexa do que comumente se supõe. Isso permite sair de uma compreensão mutilada onde só havia a essência e resgatar uma relação dialógica entre esta e a existência, colocando-as em um processo gerador e criativo dos percursos individuais e sociais. É certo que alguns autores (Gonzalez Rey, 1997; Mahoney, 1991) já têm buscado desenvolver algumas construções nesse sentido, de modo a não banalizar a perspectiva construtivista, desprezando as dimensões mais constitutivas dos sujeitos. Mesmo assim, a hipnose não deixa de possuir seu lugar cativo nessa discussão, particularmente pelas possibilidades que seus processos de influência e comunicação têm sugerido (Melchior, 1998; Roustang, 1991).

8 Sentidos são, aqui, compreendidos como complexos simbólico-emocionais marcados por várias emoções e significados distintos, mas com uma qualidade dominante (Gonzalez Rey, 2002).

9 A regra de associação livre e a regra de abstinência.

10 Deve-se ressaltar que tal ostracismo também está profundamente ligado ao parentesco histórico que a hipnose possui com o magnetismo e a parapsicologia (Carroy, 1991).

\section{A Autoridade do Terapeuta: 0 Controle que Liberta}

Para Freud (1917-a), a hipnose era um tipo de tratamento em que a autoridade do terapeuta se opunha ao sintoma, numa forma de batalha em que seria necessário que aquela se impusesse e superasse a persistência deste. Tornavam-se muito comuns os reaparecimentos dos sintomas, as novas investidas médicas e, em conseqüência, um considerável número de fracassos. Somadas ao cansaço que tal procedimento promovia, havia ainda crenças um tanto quanto questionáveis que foram ganhando espaço, como a facilidade de uma técnica que pouco exigia do terapeuta e do paciente e os riscos de uma abordagem que poderia levá-los ao vício e roubar-lhes a autoconfiança sem conseguir resultados patentes (p. 525). A hipnose ainda apresentaria a grave falha de não permitir o trabalho das resistências, podendo mesmo reforçá-las a ponto de dificultar ainda mais o acesso às causas dos problemas. Por essas razões, era necessário que o terapeuta fosse retirado dessa posição incômoda e arriscada para ser situado na posição do analista, que, por meio de um setting particular e com regras específicas ${ }^{9}$, não teria como objetivo impor-se aos sintomas, mas ajudar a tornar o inconsciente consciente de modo a facilitar as próprias soluções dos sujeitos.

Todas essas reservas à hipnose, assim como o triunfo vitorioso da Psicanálise, impuseram-se às escolas de Psicologia Clínica com o estatuto de realidade patente (Chertok \& Stengers, 1999; Neubern, no prelo), sem que se considerassem outras nuances importantes do problema. A princípio, a hipnose consistia em um simples procedimento técnico, e boa parte de seus críticos tomaram-na como uma técnica em si mesma, sem diferenciá-la dos pressupostos equivocados em que se baseava sua aplicação. Seu uso, ao menos segundo a história que triunfou nessa batalha, parecia estar indissociavelmente ligado a uma autoridade inconteste que deveria impor-se de modo direto sobre o psiquismo do paciente, cujo papel seria o de uma passividade profunda. No jogo de forças que se travava, a comunidade científica passou a assistir, cada vez mais, a numerosos fracassos, o que a levou a concluir pela inadequação das abordagens hipnóticas. Assim, todo seu potencial clínico, teórico e epistemológico passou a ser desprezado, sem que se considerasse que tal abordagem poderia ser compreendida dentro de outros princípios e possibilidades de aplicação. $\bigcirc$ que muito surpreende nesse sentido é que as obras de autores importantes que poderiam opor-se a tais pressupostos (Delboeuf, 1890/1992; Puységur, 1784/ 2003) foram lançadas ao esquecimento e só agora parecem estar sendo de novo alvo de interesse (Stengers, 2001) ${ }^{10}$.

Por outro lado, uma das significativas inovações propostas por Erickson foi a compreensão de que, para as relações humanas em geral, a abordagem indireta costuma ser mais eficiente e interessante, dentre outros motivos, pelo fato de envolver o sujeito de modo participativo (Erickson \& Rossi, 1979). Assim, esse autor desenvolveu um conjunto de técnicas de uso da linguagem (a linguagem indireta) cujos objetivos eram criar um contexto favorável para que o sujeito se engajasse no processo e criasse, via inconsciente, as soluções necessárias para suas demandas. Essa proposta pode comparar o sujeito com a noção de sistemas auto-regulados (Morin, 1990), que mantêm uma relação paradoxal de autonomia-dependência com o mundo, de modo que as relações que 
desenvolve com os diferentes contextos são qualificadas em função dos recursos e processos que lhe_são próprios. Em outras palavras, o sujeito não responde simples e linearmente às influências do mundo, mas requalifica e reconstrói essas influências de acordo com as leis e organizações desenvolvidas no seio de sua própria subjetividade. Trata-se de uma noção que tem ganhado espaço em várias escolas de psicoterapia (Gonzalez Rey, 2002; Mahoney, 1991) e que parece ser bastante familiar a boa parte das escolas de Psicologia Clínica.

Porém, o que chama atenção no caso aqui discutido é que, para desencadear mudanças, o terapeuta não abriu mão de sua autoridade, mas situou-a no setting como um dos recursos de criação de um contexto favorável para a criação de soluções do sujeito. O terapeuta percebeu que se tratava de um homem que já havia sido bastante desqualificado em seu sofrimento e com quem seria muito difícil travar um diálogo com ordens e prescrições diretas. Logo, ao construir um contexto em que três especialistas médicos conversavam entre si sem se dirigirem ao paciente, várias dimensões do problema estavam sendo contempladas. Nas mensagens que lhe eram comunicadas de forma indireta, os terapeutas simplesmente falavam sobre um referente (sua doença) sem uma comunicação direta e explícita com o receptor (o paciente), o que provavelmente Ihe permitiu uma posição mais confortável, de onde seria possível visualizar seu problema como algo externo. Quando isso ocorre, existe já uma considerável possibilidade de mudança, porque o paciente pode perceber várias formas de relação com seu problema, como as influências que sofre e a sua participação nessa relação (White \& Epston, 1993). Esse processo de significativa importância é construído no cenário dos sujeitos por várias implicações subliminares captadas prioritariamente em termos inconscientes.

Na mesma perspectiva, o terapeuta encontrou uma forma muito específica de situar a autoridade: a descrição do que seria um processo natural do corpo. Dito de outro modo, não era sobre ele que estaria a ordem de substituir o sintoma, mas sobre um processo comum de evolução da cura de um problema físico, o que foi discutido de modo didático e pausado por três especialistas que, vez por outra, recorreram a vários termos técnicos para reforçarem suas posições. Seria a natureza a responsável pela evolução clínica de uma síndrome que, no entanto, não existia organicamente. Sendo assim, enquanto o paciente concordava conscientemente com uma descrição técnica e não-ameaçadora, seus processos inconscientes permitiram a evolução da cura de acordo com os passos descritos nessas mesmas explicações. Para o paciente, enquanto a construção de uma narrativa voltada para o psíquico possuía um sentido altamente negativo e acusatório, a narrativa voltada para o funcionamento do corpo the permitia situar-se numa posição permeada de possibilidades ${ }^{11}$. Acresce-se, ainda, que a linguagem hipnótica, quando desenvolvida com possibilidades de confirmação e certeza, consiste em um recurso interessante no sentido de reforçar as sugestões. Logo, os relaxamentos que comumente decorrem de uma situação de transe foram, nesse caso, qualificados como o início de um processo de mudança.

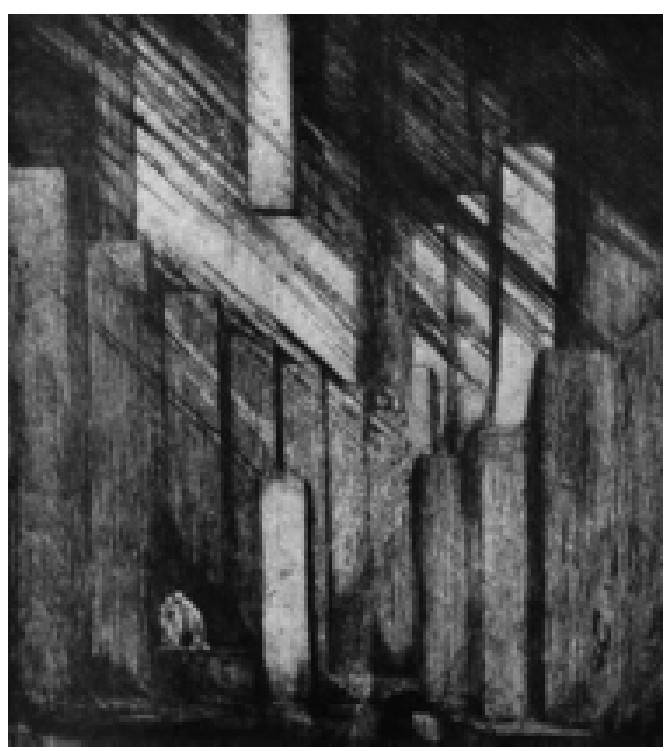

Uma leitura mais atenciosa poderia apontar um certo paradoxo quanto a tais afirmações, uma vez que, seja na substituição do sintoma, seja na eliminação de boa parte da paralisia, o paciente pareceu obedecer às sugestões do terapeuta. Essa discussão é polêmica e poderia estender-se sobremaneira, pois o caso não permitiria concluir que o paciente tenha re-significado suas experiências e sentidos. Sem dúvida, trata-se de um ponto importante que não deve ser deixado de lado e merece outros momentos para ser aprofundado (Neubern, no prelo). Contudo, o que tal afirmação não considera é que houve um trabalho ativo e inconsciente do sujeito no sentido de acatar as sugestões tal como prescritas pelos médicos e colocá-las em prática. Esse tipo de mudança foi bastante interessante, porque permitiu a continuidade de um sintoma (talvez importante para a economia psíquica do sujeito), mas de um modo restrito. Então, uma vez que o sintoma foi restrito a uma parte específica do corpo (o pulso), tornou-se possível a realização de um processo de cura na maior parte afetada (o braço). Assim, é
Para o paciente, enquanto a construção de uma narrativa voltada para o psíquico possuía um sentido altamente negativo e acusatório, a narrativa voltada para o funcionamento do corpo Ihe permitia situar-se numa posição permeada de possibilidades

11 É indubitável que este caso traz importantes questões éticas, como a manipulação do paciente, que tem sido discutida por alguns autores (McNamme \& Gergen, 1998). Entretanto, o que se busca discutir são apenas os princípios terapêuticos e sua respectiva utilização. 
possível considerar que, nesse caso, o paciente acatou as sugestões indiretas, mas não foram estas que efetivaram a cura, pois, para tanto, foi necessária a considerável participação dos processos auto-regulados do sujeito.

Em suma, a hipnose não sugere a necessidade de uma abordagem autoritária, nem o abandono de toda e qualquer autoridade, o que seria impossível em termos terapêuticos. Ela simplesmente situa essa autoridade como um recurso favorável à criação de um contexto que permita ao sujeito utilizar seus potenciais de cura e solução. Da mesma forma, os pacientes não são elementos passivos nas relações sugestivas, pois mesmo que se entreguem ao sono do transe, seus processos continuam ativos e presentes de modo a interagirem intimamente com o contexto que os cerca. Trata-se, sem dúvida, de um desafio clínico e epistemológico reconhecer que a hipnose, longe de eliminar a condição de sujeito dos pacientes, coloca-a como um dos pontos mais importantes de reflexão. Por essas razões, compreende-se que as histórias contadas pelos terapeutas a seus pacientes em transe não são mais que referências oferecidas para que estes possam pautar e direcionar os recursos de que dispõem. É por isso que se pode considerar que as histórias não curam, mas acabam por se tornar caminhos que permitem aos pacientes o encontro de soluções próprias para suas demandas ${ }^{12}$. Os caminhos são oferecidos, mas o trabalho e a caminhada são efetivados pelos próprios sujeitos.

\section{Conclusão: para que a História Seja Reescrita e Recontada}

O que o presente artigo buscou ilustrar foi que a hipnose não consiste em uma técnica em si mesma, mas que seu uso depende intrinsecamente dos pressupostos que a antecedem e a permeiam em sua prática. Assim, a palavra hipnose não deve sugerir conclusões apressadas como se, uma vez pronunciada, já fosse possível conceber todas as facetas de seus processos, até mesmo porque ainda não consiste em um assunto estudado com freqüência e profundidade na maior parte das comunidades de psicólogos. O que essa discussão leva a pensar é que a importância da hipnose abrange não só a prática clínica como também as próprias racionalidades dominantes na Psicologia (Stengers, 1993; 2001). Por um lado, remete a um amplo campo de aplicações e traz uma infinidade de recursos capazes de promover um processo terapêutico legítimo, ético e eficiente (Bellet, 1992; Melchior, 1998). Mais que isso, aponta para novas possibilidades de compreender e fazer a clínica, principalmente pelo fato de resgatar dimensões que pareciam ter sido lançadas ao lixo da história, como a sugestão e a influência (Erickson \& Rossi, 1980). Contudo, ela remete também à própria origem de uma clínica científica, principalmente porque foram os fenômenos magnéticos, sonambúlicos e hipnóticos dos séculos XVII e XVIII, na França, que impulsionaram e justificaram a criação de uma ciência psicológica nesse sentido (Carroy, 1991). Acompanhando-se o pensamento de Chertok (1989), pode-se dizer que a hipnose sempre esteve presente na clínica, desde sua origem histórica até suas práticas cotidianas atuais, embora não reconhecida nessas últimas.

Entretanto, a hipnose implica um universo de contradições para a Psicologia que remetem a muitos questionamentos: se ela apresenta tantas possibilidades clínicas, por que é marcada por tantos preconceitos? Se ela se apresenta como um dos principais eixos da origem da Psicologia, por que tantos autores que a preconizaram são desconhecidos $^{13}$ da grande maioria dos psicólogos? Por que tantas de suas práticas, como as de Delboeuf e Puységur, que poderiam trazer reflexões pertinentes para os clínicos atuais, raramente são mencionadas nos livros de história da Psicologia ou ainda raramente são discutidos nas formações e universidades? Essa lista de perguntas, que poderia ser bem maior, não encontra ainda respostas precisas, mas certamente esbarra no projeto de uma psicologia científica para a qual a hipnose representou ameaça e perigo à confiabilidade (Chertok \& Stengers, 1999; Stengers, 2001). Em outros termos, em nome da ciência e da razão, foi necessário que a Psicologia negasse a si mesma e à sua origem, contando uma história mutilada e cheia de lacunas. É como se ela devesse seguir os passos do mito de Narciso para poder manter-se viva no cenário científico (Neubern; no prelo).

A Psicologia está, por isso mesmo, diante de um grande desafio - o de poder recontar a sua história, apresentando novas alternativas e possibilidades a partir dessas origens que se tornaram marginais. Acompanhando a necessidade atual de reflexão epistemológica que incide sobre grande parte das ciências (Morin, 1991; Santos, 2000), a Psicologia pode ser comparada aos pacientes que procuram seus clínicos, pois necessitam de um trabalho terapêutico que envolve auto-reflexão, mas que, freqüentemente, mostram-se resistentes e temerosos quanto a essa possibilidade, embora não deixem de conceber que é preciso rever as próprias origens e representações para que sejam construídos novos significados. O que resultará desse desafio é, no momento, impossível de prever, até por se tratar de um ponto nevrálgico da história desse projeto de ciência. No entanto, espera-se que a Psicologia possa levar a cabo, para si mesma, a tarefa terapêutica de reflexão que seus clínicos propõem para as pessoas no cotidiano. 
Maurício Neubern

SQS 411 Bloco C Apartamento 101

70277-030 Brasília - DF

E-mail: mneubern@hotmail.com

Recebido 18/09/03 Aprovado 29/09/04

ANDERSON, H. Conversation, Language and Possibilities. New York: Basic Books, 1997.

\section{BELLET, P. L'Hypnose. Paris: Odile-Jacob, 1992.}

CARROY, J. Hypnose, Suggestion et Psychologie. L'Invention du Sujet. Paris: Puf, 1991.

CHERTOK, L. Hypnose et Suggestion. Paris: Puf, 1989.

CHERTOK, L. \& STENGERS, I. Le Coeur et la Raison. L'Hypnose en Question, de Lavoisier à Lacan. Paris: Payot, 1989.

Le Plessis Robinson: Synthelabo, 1999.

L'Hypnose: la Blessure Narcissique.

DELBOEUF, J. Le Magnétisme Animal. À Propos d'une Visite à l'Ecole de Nancy. Paris: Fayard, 1992 (originalmente publicado em 1890).

ERICKSON, M. \& KUBIE, L. The Sucessful Treatment of a Case of Acute Hysterical Depression by a Return Under Hypnosis to a Critical Phase of Childhood. Psychoanalitic Quarterly, 10, n. 4,1941, pp.122-144.

ERICKSON, M. H. Deep Hypnosis and its Induction. In L. LeCron Experimental hypnosis. New York: Macmillan, 1952, pp.70-114.

Special Techniques of Brief Hypnotherapy. Journal of Clinical and Experimental Hypnosis, 2, 1954, pp.109-129.

ERICKSON, M. \& ROSSI, E. Hypnotherapy: an Exploratory Casebook. New York: Irvington, 1979. Erickson. New York: Irvington, 1980.

The Collected Papers of Milton $\mathrm{H}$

FREUD, S. Sobre a Psicoterapia. In S. Freud Edição Standard das Obras Psicológicas Completas de Sigmund Freud. Vol. VII. Rio de Janeiro: Imago 1996, pp. 239-251(1905).

A Terapia Analítica. In S. Freud Edição Standard das Obras Psicológicas Completas de Sigmund Freud. Vol XVI . Rio de Janeiro: Imago, 1996, pp.523-539 (1917).

. Fixação em Traumas - o Inconsciente. In S. Freud Edição Standard das Obras Psicológicas Completas de Sigmund Freud. Vol XVI . Rio de Janeiro: Imago, 1996, pp.323-336 (1917).

. Análise Terminável e Interminável. In S. Freud Edição Standard das Obras Psicológicas Completas de Sigmund Freud. Vol XXIII . Rio de Janeiro: Imago ,1996, pp. 247-287(1937).

GERGEN, K. Realidad y Relaciones. Barcelona: Paidós,1996.

GERGEN, K. \& KAYE, J. Além da Narrativa na Negociação do Sentido Terapêutico. In S. McNamme \& K. Gergen. A Terapia Como Construção Social. Porto Alegre: Artes Médicas, 1998.
GONZALEZ REY, F. Sujeito e Subjetividade. São Paulo: Thomson, 2002.

Referências

GRANDESSO, M. Sobre a Reconstrução do Significado. São Paulo: Casa do Psicólogo, 2002.

HALEY, J. Uncommun Therapy. The Psychiatric Techniques of Milton $\mathrm{H}$. Erickson. New York: Norton \& Company, 1993.

MAHONEY, M. Human Change Process. New York: Basic Books, 1991.

MCNAMME, S. \& GERGEN, K. A Terapia Como Construção Social. Porto Alegre: Artes Médicas, 1998.

MELCHIOR, T. Créer le Réel. Paris: Seuil, 1998.

MORIN, E. Science avec Conscience. Paris: Seuil, 1990.

La Méthode IV. Les Idées. Paris: Seuil, 1991.

NEUBERN, M. Milton Erickson e o Cavalo de Tróia: a Terapia não Convencional no Cenário da Crise dos Paradigmas em Psicologia Clínica. Psicologia: Reflexão e Crítica, 15, n. 2, 2002, pp. 363 - 372.

. La Psychologie Clinique: du Malaise aux Possibilités Épistémologiques. Psychothérapies, 23, n. 2, 2003, pp. 81 -88.

Complexidade e Psicologia Clínica: Desafios Epistemológicos. Brasília: Plano(no prelo).

O'HANLON, W. Raízes Profundas. Campinas: Psy II,1994.

PUYSÈGUR, A. M. J. Mémoires Pour Servir à l'Histoire et à l'Établissement du Magnétisme Animal. Paris: Imago, 2003 (originalmente publicado em 1784).

ROBLES, T. Concerto Para Quatro Cérebros em Psicoterapia. Belo Horizonte: Ed. Diamante, 2001.

ROUSTANG, F. L'Influence. Paris: Minuit, 1991

SANTOS, B. S. A Crítica da Razão Indolente. São Paulo: Cortez, 2001.

STENGERS, I. L'Importance de I'Hypnose. Le Plessis Robinson: Synthèlabo, 1993.

Qu'est-ce que l'Hypnose nous Oblige à Penser. Ethnopsy, 3, 2001, pp.13-68.

WHITE, M. \& EPSTON, D. Medios Narrativos Para Fines Terapéuticos. Barcelona: Paidós, 1993.

Yapko, M. Hypnosis and the Treatment of Depressions. New York: Brunner/Mazel, 1992. 